\title{
Analysis of Chemically Labile Glycation Adducts in Seed Proteins: Case Study of Methylglyoxal-Derived Hydroimidazolone 1 (MG-H1)
}

\author{
Kristina Antonova ${ }^{1,2,+}$, Maria Vikhnina ${ }^{1,2,+}$, Alena Soboleva ${ }^{1,2,+} \mathbb{D}$, Tahir Mehmood ${ }^{1}$, \\ Marie-Louise Heymich ${ }^{3}$, Tatiana Leonova ${ }^{2}$, Mikhail Bankin ${ }^{4}$, Elena Lukasheva ${ }^{2}$ (D), \\ Sabrina Gensberger-Reigl ${ }^{3} \mathbb{D}$, Sergei Medvedev ${ }^{4}$, Galina Smolikova ${ }^{4}{ }^{\mathbb{D}}$, Monika Pischetsrieder ${ }^{3}$ \\ and Andrej Frolov 1,2,* \\ 1 Department of Bioorganic Chemistry, Leibniz Institute of Plant Biochemistry, 06120 Halle, Germany \\ 2 Department of Biochemistry, St. Petersburg State University, 199004 St. Petersburg, Russia \\ 3 Department of Chemistry and Pharmacy, Food Chemistry, Friedrich-Alexander Universität \\ Erlangen-Nürnberg (FAU), 91058 Erlangen, Germany \\ 4 Department of Plant Physiology and Biochemistry, St. Petersburg State University, \\ 199034 St. Petersburg, Russia \\ * Correspondence: a.a.frolov@spbu.ru or andrej.frolov@ipb-halle.de; Tel.: +49-(0)-345-5582-1350 \\ + These authors contributed equally to this work.
}

Received: 7 December 2018; Accepted: 24 July 2019; Published: 26 July 2019

check for updates

\begin{abstract}
Seeds represent the major source of food protein, impacting on both human nutrition and animal feeding. Therefore, seed quality needs to be appropriately addressed in the context of viability and food safety. Indeed, long-term and inappropriate storage of seeds might result in enhancement of protein glycation, which might affect their quality and longevity. Glycation of seed proteins can be probed by exhaustive acid hydrolysis and quantification of the glycation adduct $N^{\varepsilon}$-(carboxymethyl)lysine (CML) by liquid chromatography-mass spectrometry (LC-MS). This approach, however, does not allow analysis of thermally and chemically labile glycation adducts, like glyoxal-, methylglyoxal- and 3-deoxyglucosone-derived hydroimidazolones. Although enzymatic hydrolysis might be a good solution in this context, it requires aqueous conditions, which cannot ensure reconstitution of seed protein isolates. Because of this, the complete profiles of seed advanced glycation end products (AGEs) are not characterized so far. Therefore, here we propose the approach, giving access to quantitative solubilization of seed proteins in presence of sodium dodecyl sulfate (SDS) and their quantitative enzymatic hydrolysis prior to removal of SDS by reversed phase solid phase extraction (RP-SPE). Using methylglyoxal-derived hydroimidazolone 1 (MG-H1) as a case example, we demonstrate the applicability of this method for reliable and sensitive LC-MS-based quantification of chemically labile AGEs and its compatibility with bioassays.
\end{abstract}

Keywords: Advanced glycation end products (AGEs); enzymatic hydrolysis; glycation; methylglyoxalderived hydroimidazolone 1 (MG-H1); seeds; seed ageing; seed quality; sodium dodecyl sulfate (SDS)

\section{Introduction}

Seeds represent the major source of food protein all over the world, and impact essentially on the daily human diet [1]. Therefore, seed quality, both in the sense of viability and food safety, needs to be secured. In this context, the conditions and duration of seed storage becomes an important factor, directly affecting seed quality [2]. It is known that prolonged or/and inappropriate storage of seeds results in dramatic enhancement of seed protein glycation, which is known to be an important 
marker of seed quality and longevity [3,4]. To some extent, this phenomenon can be simulated by a well-established model of accelerated ageing [5].

Glycation is a ubiquitous process of protein modification, accompanying interaction of amino and guanidino groups of polypeptides with carbonyl compounds (predominantly reducing sugars and $\alpha$-dicarbonyls) [6], and yielding advanced glycation products (AGEs) [7]. These structurally diverse species are well-detectable in mammalian tissues $[8,9]$ and are readily generated during thermal treatment of foods [10]. Accumulation of AGEs in mammalian organism results in intensive interand intra-molecular protein cross-linking [11], and triggers expression of molecular pro-inflammatory factors via interaction with multi-ligand immunoglobulin-like receptors (e.g., RAGEs-receptors to AGEs) [12]. Resulting sub-clinical inflammation accompanies ageing and related atherosclerotic changes in tissues [13], which ultimately contribute to the pathology of diabetes mellitus and neurodegenerative disorders, like Alzheimer and Parkinson diseases [14-16]. Last decade, protein glycation was reported in plants [17]. A deeper analysis of plant glycated proteome revealed a strong prevalence of AGE formation over early glycation [18]. Moreover, glycation of specific proteins was enhanced not only in presence of environmental stressors, like drought [19], but also accompanied ageing in leaves [20], legume nodules [21] and seeds [22].

Methylglyoxal (MGO)-derived hydroimidazolones are the products of non-enzymatic reaction of this $\alpha$-dicarbonyl with arginyl residues of proteins, and are represented with three isomers, namely $-\mathrm{N}^{\delta}$-(5-methyl-4-oxo-5-hydroimidazo-linone-2-yl)-L-ornithine (MG-H1, the major adduct) [23], 2-amino-5-(2-amino-5-hydro-5-methyl-4-imidazolon-1-yl)pentanoic acid (MG-H2) and 2-amino-5-(2-amino-4-hydro-4-methyl-5-imidazolon-1-yl)pentanoic acid (MG-H3) [24]. According to the formation pathway, proposed by Glomb and co-workers [25] and confirmed at the peptide level [26], reaction of arginyl residues with methylglyoxal yields an intermediate-methylglyoxal-derived dihydroxyimidazolidine (Figure 1). Its dehydration results in formation of MG-H3, which can be reversibly hydrolyzed to $N^{\delta}$-(carboxymethyl)arginine under alkaline conditions [27]. Further re-condensation and formation of the hydroimidazolone ring yields the major product MG-H1, whereas involvement of the second MGO molecule in the reaction with dihydroxyimidazolidine results in formation of $N^{\delta}$-(5-hydroxy-4,6-dimethylpyrimidine-2-yl)-L-ornithine (argpyrimidine) [28] and $N^{\delta}$-(4-carboxy-4,6-dimethyl-5,6-dihydroxy-1,4,5,6-tetrahydropyrimidine-2-yl)-L-ornithine(tetra-hydropyrimidine) [29].

Quantification of free MG-H isomers in biological samples typically relies on chromatographic techniques with fluorescence [30] or tandem mass spectrometry (MS/MS)-based detection [31]. To assess the contents of protein-bound adducts, exhaustive hydrolysis of corresponding polypeptides needs to be done [9]. Thereby, standard isotope dilution and standard addition represent the "gold standard" in quantitative analysis of AGEs in biological matrices [32]. In the most easy and straightforward way, quantitative hydrolytic degradation of any intra- and extra-cellular protein can be achieved by acid hydrolysis in presence of $6 \mathrm{~N} \mathrm{HCl}$ at $100-110^{\circ} \mathrm{C}(18-24 \mathrm{~h})[33,34]$. This method is well-applicable to seeds, and allows complete degradation of total protein isolates, which are typically only partly soluble in aqueous solutions and cannot be adequately addressed by enzymatic techniques. However, as up to $90 \%$ hydroimidazolones degrade under conditions of acid hydrolysis [24], analysis of these products by multi-step enzymatic degradation procedures represents the only option to address AGE contents in biological samples. Whereas for some insoluble proteins, like collagen, this can be achieved [35], for complex multi-protein mixtures, like preparations of total seed protein, it could not be done so far. Therefore, here we propose a modified enzyme-based protocol, giving access to quantitative hydrolysis of total seed protein, and compatible both with LC-MS-based absolute quantification techniques and biological assays. 

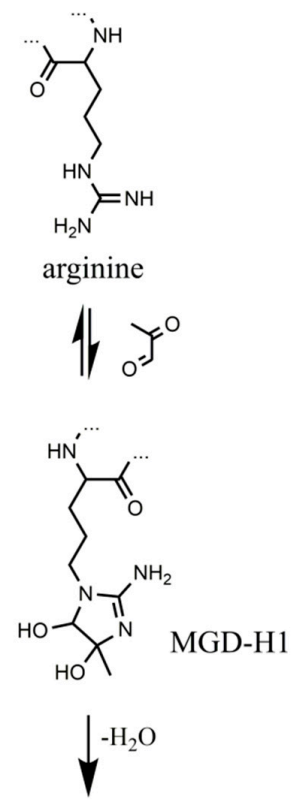

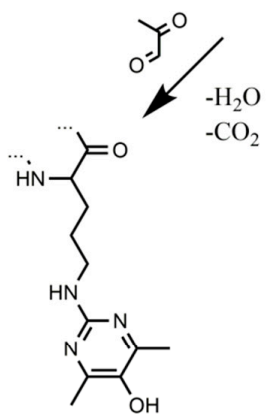

argpyrimidine
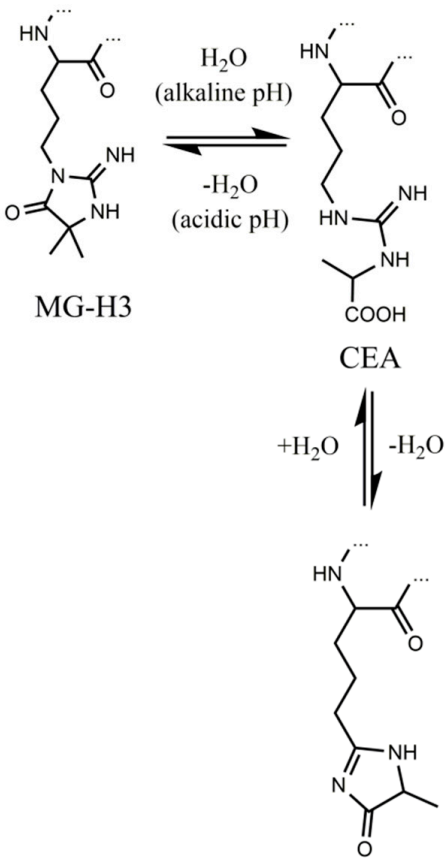

MG-H1

Figure 1. Formation and transformation of methylglyoxal-derived advanced glycation end products (AGEs). The "..." sign indicates polypeptide chain.

\section{Results}

\subsection{Protein Isolation and Enzymatic Hydrolysis}

As pea seeds represent a protein-rich matrix, the protein extraction method was optimized in respect to the tissue amounts, taken for the phenol extraction. The maximal protein recovery (91.6 $\pm 22.5 \mathrm{mg}$ protein/g fresh weight) could be achieved with the sample amount of $50 \mathrm{mg}$ (Figure S1). Therefore, pea proteins were isolated from approximately $50 \mathrm{mg}$ of frozen embryos $(n=3)$. The oilseed rape seeds $(n=5)$ were isolated in two portions, which were combined afterwards.

As expected, the protein isolates could be only partly reconstituted in aqueous buffers (Tris-HCl buffer or phosphate buffered saline, PBS). Therefore, to achieve quantitative protein hydrolysis, we 
decided for reconstitution of the isolates in presence of a detergent $(10-20 \%(v / v)$ Triton X-100 or 10\% $(w / v)$ sodium dodecyl sulfate, SDS), which was supposed to be diluted prior to hydrolysis and removed afterwards. While application of Triton X-100 did not result in complete reconstitution of protein pellets, it was the case with the SDS solution. Determination of protein contents in aq. $10 \%(w / v)$ SDS revealed the extraction yields in the range of 39.6-66.6 and 19.4-28.4 mg/g fresh weight for pea and oilseed rape seeds, respectively (Tables S1 and S2). The assay precision was determined by SDS-PAGE loading $5 \mu \mathrm{g}$ of protein on each lane: the overall lane densities were $3.1 \times 10^{4} \pm 6.0 \times 10^{3}$ arbitrary units $(\mathrm{AU}, \mathrm{RSD}=19.3 \%)$ and $2.9 \times 10^{4} \pm 9.2 \times 10^{2} \mathrm{AU}(\mathrm{RSD}=3.2 \%)$ for pea and oilseed rape, respectively.

After a 20-fold dilution with phosphate buffered saline, the resulted concentration of SDS $(0.5 \%$ $w / v)$ was compatible with the activities of pronase $\mathrm{E}$, proteinase $\mathrm{K}$ and carboxypeptidase $\mathrm{Y}$. Therefore, the protocol, established in the Glomb's group [9], could be successfully employed here. SDS-PAGE showed no protein signals already after the first incubation with pronase E (Figure S2). The applicability of the method was further confirmed with heavily glycated bovine serum albumin (BSA, Figure S3). Syringe infusion analysis of the aliquots sampled after the completion of the hydrolysis (but before SPE), revealed no multi-charged signals, potentially corresponding to non-digested peptides (Figure S4). Thus, the hydrolysis of seed protein could be considered to be exhaustive and quantitative.

\subsection{Removal of the Detergent by Solid Phase Extraction}

For the removal of the detergent we considered solid phase extraction (SPE) on three CHROMABOND materials-reversed phase (C18), weak and strong anion exchangers (HR-XAW and HR-XA, respectively). For this, mixtures of three basic amino acids, known as precursors of AGEs (lysine, arginine and histidine) were loaded on all three cartridges according to the instructions of the producer (Protocols S1-3). After derivatization with $N^{2}$-(5-fluoro-2,4-dinitrophenyl)-L-valine amide (L-FDVA) according a well-established protocol [36], amino acid derivatives were analyzed by RP-UHPLC-ESI-LIT-Orbitrap-MS. Among the three tested SPE protocols, the strong anion exchanger showed poor recovery for lysine and histidine $(16 \%$ and $45 \%$ in combined flow-through and wash fractions, respectively, Figure S5A), whereas the weak anion exchanger showed good recoveries for all analytes, but a strong signal enhancement effect for lysine was observed (Figure S5B). FIA-HR-MS analysis indicated quantitative retention of SDS by both phases. The reverse phase cartridges showed good recovery for histidine and arginine, whereas for lysine it was slightly compromised $(57 \%$, Figure S5C). Thereby, to ensure quantitative elution of all amino acids, two wash steps were used in this system - with $25 \mathrm{mmol} / \mathrm{L}$ ammonium acetate and with $100 \mathrm{mmol} / \mathrm{L}$ ammonia. FIA-HR-MS analysis showed that SDS was quantitatively retained on the cartridge in absence of acetonitrile in the eluent. However, only $10 \%(v / v)$ acetonitrile in eluent mixture resulted in partial elution of SDS from the cartridge and contamination of the amino acid sample. Remarkably, when $200 \mu \mathrm{g}$ of hydrolyzates, obtained from glycated BSA were loaded on C18 cartridges with and without spiking with $0.5 \%(w / v)$ SDS $(n=4)$, no effect of SDS on signal intensities in subsequent LC-MS analyses was observed (Figure S6).At the next step we considered the performance of C18 cartridges with and without endcapping. For this, $200 \mu \mathrm{g}$ of glycated BSA in $1 \mathrm{~mL}$ of PBS were loaded on CROMABOND C18 cartridges with and without endcapping either with or without pre-spiking with SDS solution to get final concentration of $0.5 \%(w / v)$. The result indicated slightly better performance of endcapped cartridges for both MG-H1 and arginine (Figure S7A,B, respectively), whereas for a hydrophobic amino acid phenylalanine an enhancement effect was observed (Figure S7C). The recoveries of CML (taken as a reference AGE) and lysine were also good, although signal enhancement for lysine was observed (Figure S8). Thus, the final SPE protocol relied on C18 endcapped cartridges and a two-step elution procedure, comprising $25 \mathrm{mmol} / \mathrm{L}$ ammonium acetate and with $100 \mathrm{mmol} / \mathrm{L}$ ammonia ( $6 \mathrm{~mL}$ each).

\subsection{RP-UHPLC-ESI-LIT-Orbitrap-MS Analysis}

Having the optimized sample preparation procedure in hand, we established a method for absolute quantification of MG-H1 in biological matrices, as a case proof of the concept experiment. 
As stable isotope dilution technique is a gold standard in analysis of glycated adducts [37], we decided on this approach here. For this, first, the amounts of MG-H1 were roughly estimated by external calibration with the authentic standard. After adjustment of the sample loading conditions (in respect to the weight of hydrolyzed protein), the amounts of MG-H1 in $100 \mu \mathrm{L}$ of injected hydrolyzates of glycated BSA and pea seed protein extracts were found to be 71 and 1 pmol, respectively. Therefore, we adjusted the amounts of the spiked internal standard (MG-H1-d3) to ensure the intensity ratio of analyte and internal standard within two orders of magnitude around 1.0. Thus, quantitative analysis could be reliable, when 10-50 pmol of internal standard were loaded on the column.

The internal standard suited well to the proposed quantification strategy. Indeed, on one hand it co-eluted with the analyte, on another, it could be clearly distinguished from the analyte by the isotopic pattern (Figure 2). Therefore, extracted ion chromatograms (XICs) could be independently calculated from both compounds, and intensity ratio could be determined in a simple and straightforward way. Tandem mass spectrometric (LIT-Orbitrap-MS/MS) analysis delivered well-interpretable fragmentation patterns (Figure 3A), which were identical for the analyte and commercially available authentic MG-H1 standard (Figure 3B). The MS/MS spectrum of the internal standard (MG-H1-d3) also reproduced the spectrum of analyte with consideration of the deuterium substitution (Figure 3C).
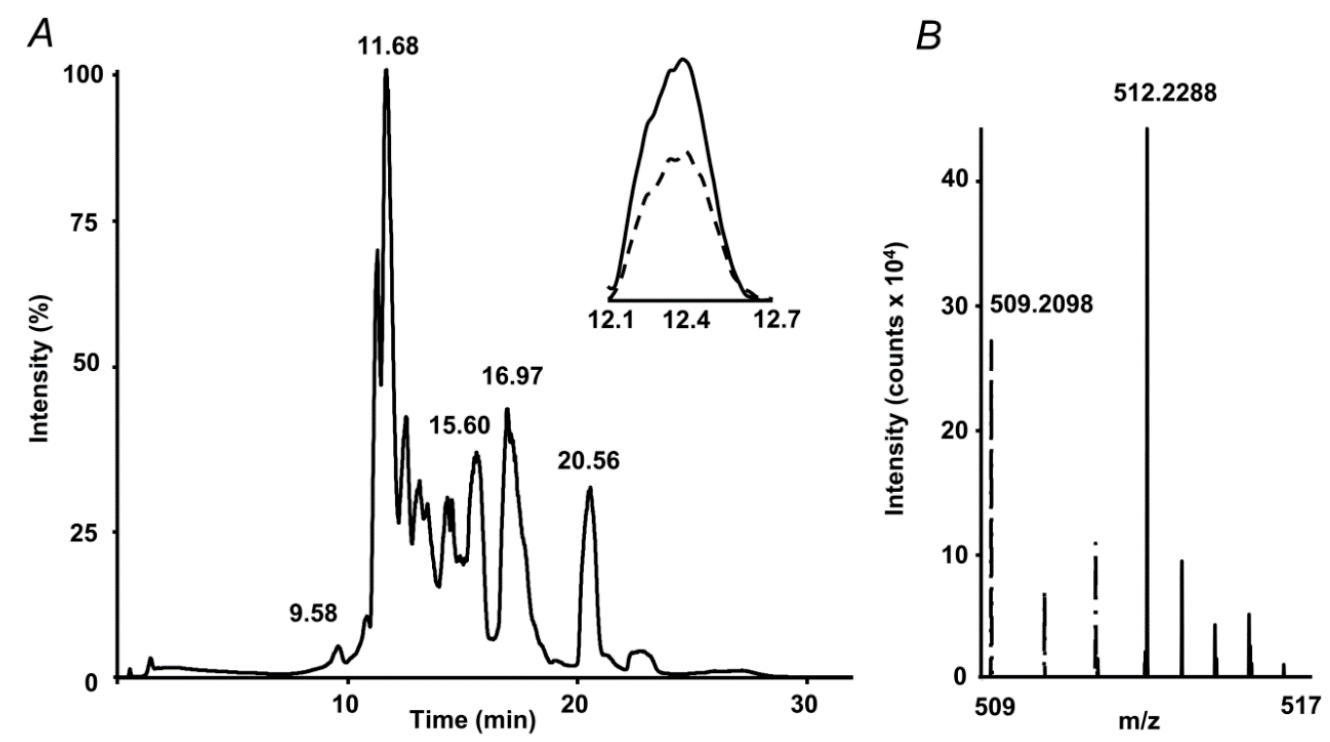

Figure 2. Absolute quantification of methylglyoxal hydroimidazolone 1 (MG-H1) adducts in protein hydrolysates by stable isotope dilution: total ion chromatogram (TIC) with extracted ion chromatograms (XICs) at $\mathrm{m} / \mathrm{z} 509.21 \pm 0.03$ (dashed) and $512.22 \pm 0.03$ (solid) corresponding to the $\left[\mathrm{M}+\mathrm{H}^{+}\right]^{+}$ions of MG-H1 and spiked MG-H1-d3 internal standard, respectively (A), and the corresponding segment of the mass spectrum, representing isotopic patterns of both isotopomers (B).

\subsection{Standardization and Validation of the Quantification Method}

The instrument LODs and LOQs of MG-H1 (determined as MG-H1-d3 spiked to BSA hydrolysate) were 2.5 and $25 \mathrm{fmol}$, respectively with linear dynamic range (LDR) of $4 \times 10^{4}$ (Table 1). It was comparable with these parameters obtained for reference amino acids-arginine, lysine, alanine and phenylalanine $\left(5-25 \mathrm{fmol}, 25-100 \mathrm{fmol}\right.$, and $0.1-1.0 \times 10^{3}$, respectively, Table S3). Thereby, the coefficient of determination $\left(\mathrm{R}^{2}\right)$ was not less than 0.988 . The method showed an excellent intra- and inter-day precision for both derivatization procedure and LC-MS analysis itself, as well as for the overall sample preparation procedure, comprising the whole enzymatic hydrolysis and SPE. Indeed, the first two values were about $1 \%$ (Tables 2 and 3), whereas the overall precision hydrolysis/SPE precision was below $8.0 \%$ (Table 4). Importantly, L-FDVA derivatives of MG-H1 showed good stability under the conditions of autosampler $\left(8{ }^{\circ} \mathrm{C}\right)$ : the alterations of the analyte recoveries were within $4 \%$, when repetitive injections from the same vial were performed during three consecutive days ( $n=4 /$ day). 
Table 1. Sensitivity and linearity parameters obtained for MG-H1 and reference amino acids.

\begin{tabular}{ccccccccc}
\hline Analyte & $m / z$ & $\mathbf{t}_{\mathbf{R}}$ & $\begin{array}{c}\text { LOD } \\
(\mathbf{f m o l})\end{array}$ & $\begin{array}{c}\text { LOQ } \\
(\mathbf{p m o l})\end{array}$ & LDR & Slope & Intercept & $\mathbf{R}^{\mathbf{2}}$ \\
\hline MG-H1-d3 ${ }^{\mathrm{a}}$ & 512.23 & 12.4 & 2.5 & 0.025 & $4.0 \times 10^{4}$ & $5.0 \times 10^{6}$ & $1.0 \times 10^{7}$ & 0.996 \\
\hline a Serial dilutions $(n=3)$ were prepared with the hydrolysate of $3 \mathrm{mg} / \mathrm{mL}$ glycated bovine serum albumin (BSA).
\end{tabular}
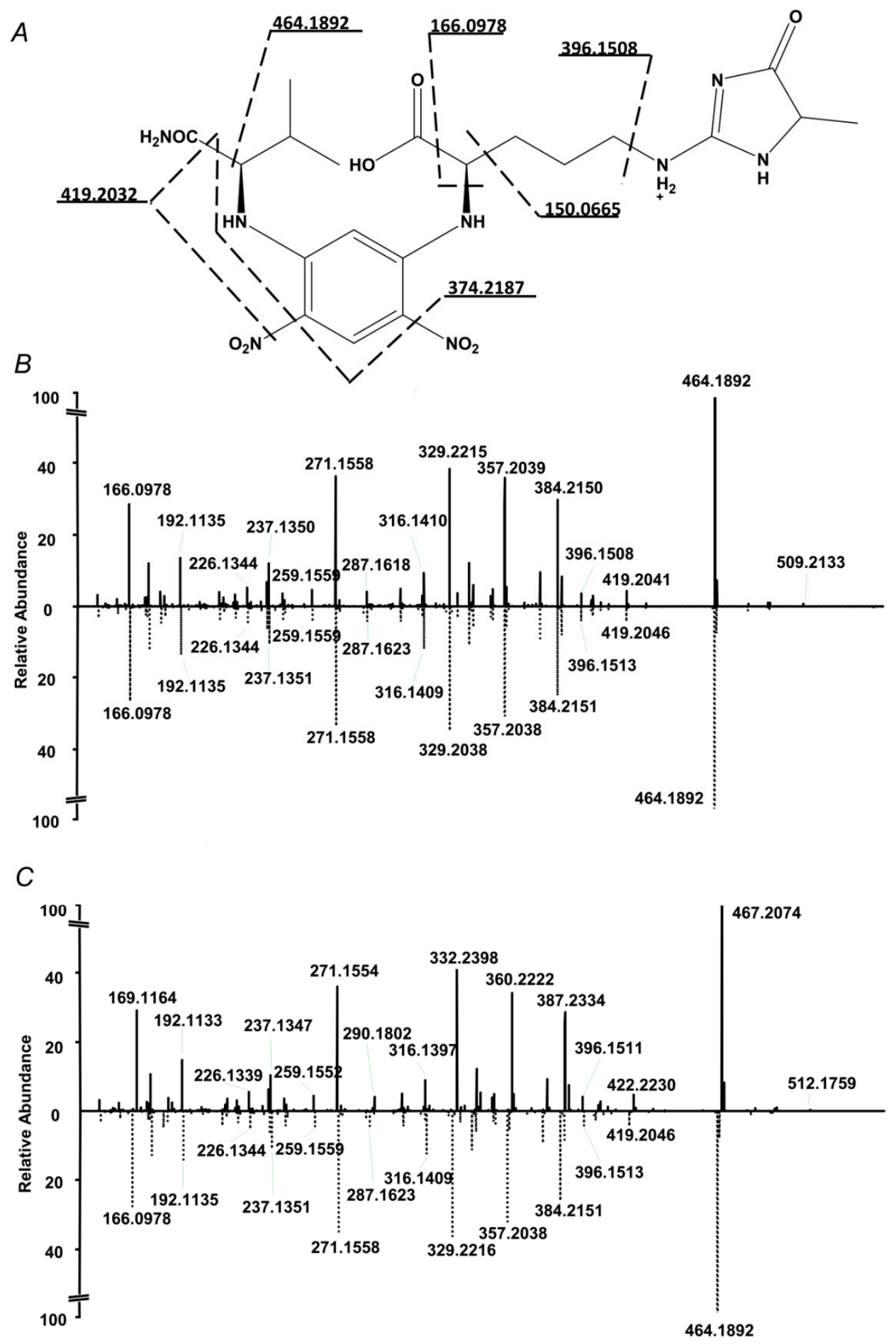

Figure 3. Fragmentation pattern of the $N^{2}$-(5-fluoro-2,4-dinitrophenyl)-L-valine amide (L-FDVA) derivative of MG-H1 in enzymatic hydrolysates of glycated BSA (A and B,C bottom) and its comparison with MS/MS spectrum of authentic MG-H1 (B top) and internal MG-H1-d3 (C top) standards. 
Table 2. Validation of the $N^{2}$-(5-fluoro-2,4-dinitrophenyl)-L-valine amide (L-FDVA) derivatization of the MG-H1 adduct with intraday and inter-day precision values determined for MG-H1 in enzymatic hydrolysates of glycated BSA ${ }^{a}$.

\begin{tabular}{ccc}
\hline Parameter & ${\text { Intraday Precision }(n=4)^{b}}^{b}$ & ${\text { Inter-Day Precision }(n=4 / \text { Day })^{c}}^{t_{\mathrm{R}}(\mathrm{min}) \pm \mathrm{SD}(\mathrm{RSD} \%)}$ \\
$\begin{array}{c}\text { content }(\mathrm{nmol} / \mathrm{mg} \text { protein }) \\
\mathrm{AV} \pm \mathrm{SD}(\mathrm{RSD} \%)\end{array}$ & $87.88 \pm 0.88(1.01)$ & $12.3 \pm 0.016(0.129)$ \\
& & $87.35 \pm 0.8(0.92)$ \\
\hline
\end{tabular}

${ }^{a}$ Validation was performed with a hydrolysate of glycated BSA spiked with internal standard MG-H1- $\mathrm{d}_{3}(25 \mathrm{pmol}$ per injection); ${ }^{b}$ the maximal RSD\% value, among those acquired on each of four consecutive validation days, is shown; ${ }^{c}$ the inter-day precision was evaluated on four consecutive days. $\mathrm{AV}$, average value; $\mathrm{ME}$, mean error; $\mathrm{RSD} \%$, relative standard deviation percentage.

Table 3. Validation of RP-UHPLC-ESI-LIT-Orbitrap-MS quantification method with intraday and inter-day precision values determined for MG-H1 in enzymatic hydrolysates of glycated BSA ${ }^{a}$.

\begin{tabular}{ccc}
\hline Parameter & ${\text { Intraday Precision }(\boldsymbol{n}=\mathbf{5})^{\boldsymbol{b}}}^{\boldsymbol{b}}$ & ${\text { Inter-Day Precision }(\boldsymbol{n}=\mathbf{5} / \text { Day })^{c}}^{c}$ \\
\hline$t_{\mathrm{R}}(\mathrm{min}) \pm \mathrm{SD}(\mathrm{RSD} \%)$ & $12.3 \pm 0.022(0.179)$ & $12.3 \pm 0.014(0.117)$ \\
content $(\mathrm{nmol} / \mathrm{mg}$ protein $)$ & $86.72 \pm 1.03(1.185)$ & $86.64 \pm 0.95(1.093)$ \\
$\mathrm{AV} \pm \mathrm{SD}(\mathrm{RSD} \%)$ &
\end{tabular}

${ }^{a}$ Validation was performed with a hydrolysate of glycated BSA spiked with internal standard MG-H1-d 3 (25 pmol per injection); ${ }^{b}$ the maximal RSD\% value, among those acquired on each of four consecutive validation days, is shown; ${ }^{c}$ the inter-day precision was evaluated on four consecutive days. AV, average value; ME, mean error; RSD $\%$, relative standard deviation percentage.

Table 4. Validation of the sample preparation procedure (enzymatic hydrolysis with subsequent solid phase extraction) with intraday and inter-day precision values determined for MG-H1 in enzymatic hydrolysates of seed protein extract ${ }^{a}$.

\begin{tabular}{|c|c|c|}
\hline Parameter & Intraday Precision $(n=3)$ & Inter-Day Precision ( $n=3 /$ Day) ${ }^{b}$ \\
\hline$t_{\mathrm{R}}(\min ) \pm \mathrm{SD}(\mathrm{RSD} \%)$ & $12.4 \pm 0.033(0.263)$ & $12.4 \pm 0.0185(0.15)$ \\
\hline content (nmol mg ${ }^{-1}$ protein) $\mathrm{AV} \pm \mathrm{SD}(\mathrm{RSD} \%)$ & $0.73 \pm 0.052(7.66)$ & $0.708 \pm 0.037(5.22)$ \\
\hline
\end{tabular}

For analysis of recovery, MG-H1-d3 was spiked to isolated pea protein in aq. $10 \%(w / v)$ SDS prior to dilution with PBS and enzymatic hydrolysis. To address the interference of the target analyte with the components of protein hydrolyzates, the recovered amounts of MG-H1-d3 were compared to those, observed when the same aliquots of MG-H1-d3 were spiked to aq. $10 \%(w / v)$ SDS, subjected to the identical treatment. To address the effect of incubations with the enzymes on glycation adduct stability, the recovered amounts of MG-H1-d3 were compared to the standard solution of MG-H1-d3, dissolved in PBS at the same concentration. The analysis revealed relatively low contribution of other hydrolysis products (i.e., highly abundant proteinogenic amino acids): a slight enhancement of detection was observed in comparison to blank hydrolysis samples (recovery 109.4\%, Figure S9). In contrast, the prolonged hydrolysis procedure itself resulted in a relatively high degree of the target analyte suppression or degradation-only $18 \%$ of MG-H1-d3 could be recovered, although this result was reliably reproducible (Figure S9).

For analysis of the possible matrix effects as a potential reason for the observed recovery loss, the approach of Böttcheret al. [38] was applied. For this, a L-FDVA derivative of the MG-H1-d3 standard $(0.2 \mu \mathrm{mol} / \mathrm{L})$ was infused with a syringe pump at $3 \mu \mathrm{L} / \mathrm{min}$ in the effluent of RP-HPLC column after injection of blank $(20 \% v / v$ aq. acetonitrile in $0.1 \% v / v$ formic acid, Figure S10) or derivatized pea protein hydrolyzate $(13.6 \mu \mathrm{g}$, Figure S11). Although no matrix effects could be detected in blank (Figure S10B), approximately complete suppression of the MG-H1-d3-L-FDVA signal was observed at $t_{R}$ 8.8-9.2 min and 11.5-12.0 min when the standard was infused in the column effluent obtained with 
pea protein hydrolyzate (Figure S11B). Thus, the section of the chromatogram, corresponding to $t_{R}$ of MG-H1 and its labeled counterpart $\left(t_{R}=12.3 \mathrm{~min}\right)$ was only minimally affected by ion suppression, i.e., the observed loss of recovery upon the hydrolysis procedure is mostly related to the compromised stability of the hydroimidazolone glycation adduct under the prolonged hydrolysis conditions.

\subsection{Quantification of MG-H1 in Seed Protein Hydrolysates by Stable Isotope Dilution}

To address the applicability of the developed quantification approach to determination of MG-H1 contents in seed proteins, we analyzed protein hydrolysates obtained from pea and oilseed rape seeds. The analysis revealed more than eight-fold higher MG-H1 levels, present in pea seeds in comparison to those determined in the oilseed rape seeds $(1.31 \pm 0.022$ vs. $0.17 \pm 0.01 \mathrm{nmol} / \mathrm{mg}$ protein, Figure 4$)$. Unexpectedly, accelerated ageing did not reveal any increase of MG-H1 seed contents (Figure 4A). In contrast, a non-significant tendency for down-regulation of this AGE was observed. On the other hand, natural ageing during nine years resulted in a slight and non-significant up-regulation of MG-H1 in the oilseed rape seeds (Figure 4B).
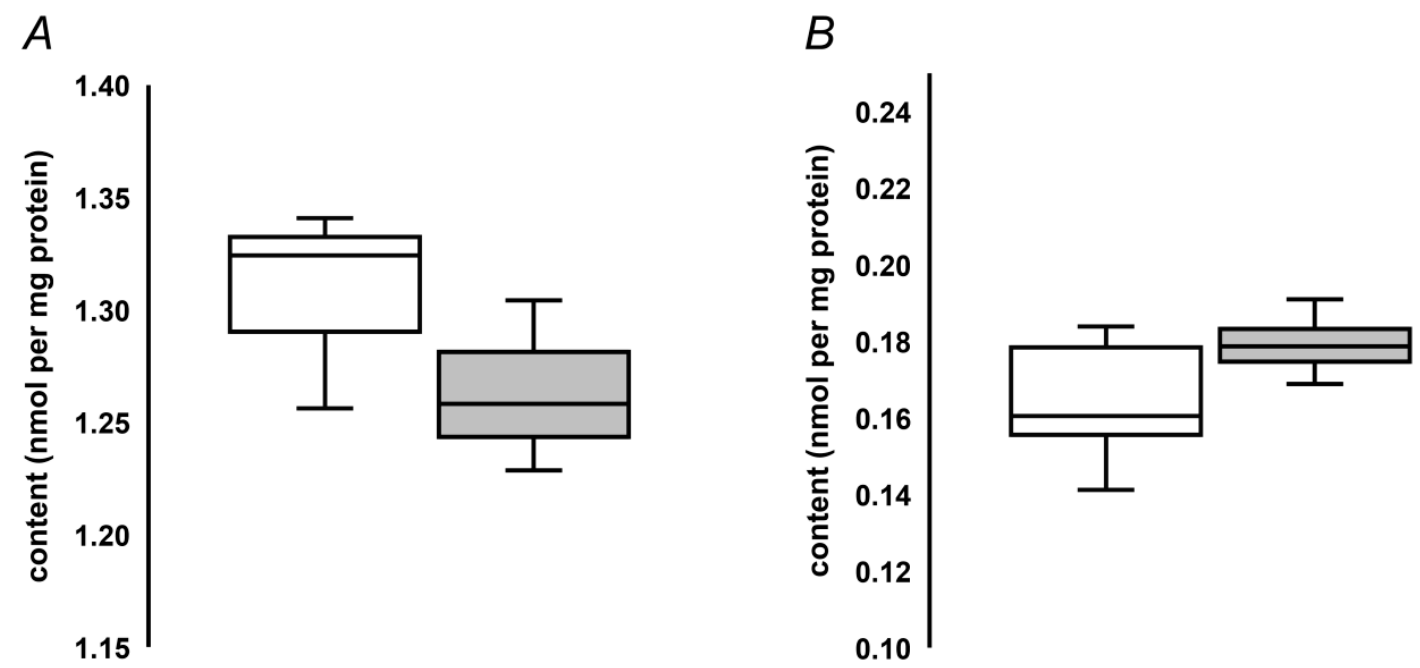

Figure 4. Quantification of MG-H1 adducts in pea seeds, subjected to accelerated ageing (5 days, $86 \%$ relative humidity, $45^{\circ} \mathrm{C}$, grey bars, $n=3$ ) along with corresponding untreated controls (white bars, $n=3, \mathbf{A}$ ), and oilseed rape seeds subjected to natural ageing at $18^{\circ} \mathrm{C}$ during nine years (grey bars, $n=5$ ) along with corresponding controls stored during one year (white bars, $n=5, \mathbf{B}$ ). The bars indicate median with the minimal and maximal values of the corresponding inter-quartile ranges.

\subsection{Compatibility of the Hydrolysis Protocol with Cell Assays}

To address the compatibility of the optimized hydrolysis protocol with biological assays, we characterized toxicity of the obtained hydrolysates for cultured neuroblastoma SH-SY5Y cells. The main aim of this section was to verify, that the degree of SDS removal with our SPE procedure is sufficient for cell assays, i.e., that residual SDS does not exert cytotoxicity, or such effects are negligible. For this, $2 \mathrm{mg}$ of lyophilized glycated BSA and protein, isolated from pea seeds, not subjected to accelerated ageing, were reconstituted in $50 \mu \mathrm{L}$ of $10 \%(w / v)$ aq. SDS and hydrolyzed as described in the Materials and Methods section. Pre-cleaned hydrolysates were freeze-dried, reconstituted in medium and different amounts of isolates were applied to cultured cells. For glycated BSA, the MTT assay did not reveal any statistically significant difference from untreated controls up to the concentration of $0.4 \mathrm{mg} / \mathrm{mL}$ (Figure 5A), whereas for pea protein a minimal reduction of cell viability $(17.1 \%)$ was observed with $0.3 \mathrm{mg} / \mathrm{mL}$ ( $t$-test: $p=0.021$ ), with no effect observed at lower concentrations (Figure 5B). 

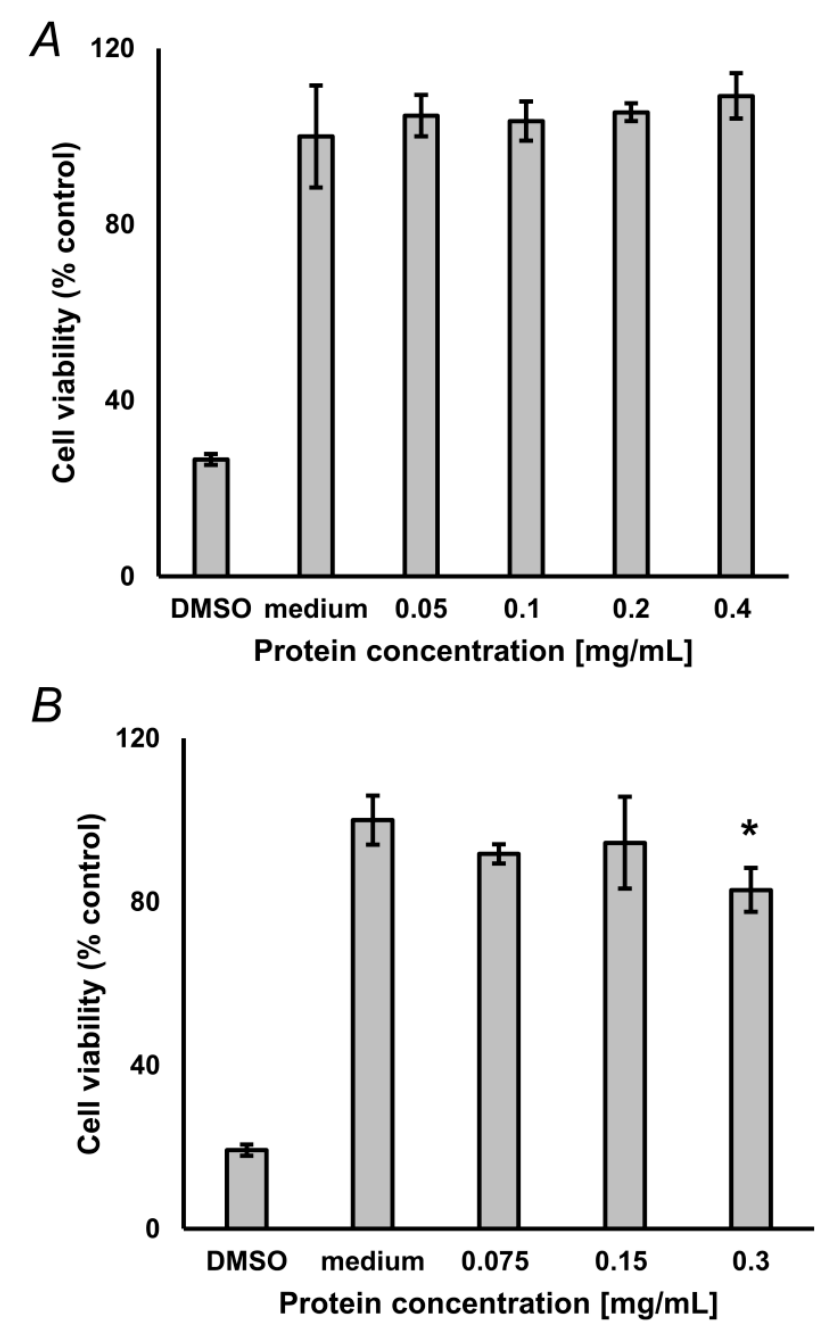

Figure 5. Results of the 3-(4,5-dimethylthiazol-2-yl)-2,5-diphenyltetra-zoliumbromid (MTT) assay, performed with $0.05-0.4 \mathrm{mg} / \mathrm{mL}$ glycated bovine serum albumin (BSA, $n=3, \mathbf{A}$ ) and $0.075-0.3 \mathrm{mg} / \mathrm{mL}$ protein isolated from pea seeds $(n=3, \mathbf{B})$, not subjected to accelerated ageing. Analyses were performed in triplicates. Culture medium served as negative control. DMSO served as positive control. * Difference was significant ( $t$-test) at the confidence level of $p<0.05$ ).

\section{Discussion}

Protein glycation impacts essentially on seed quality and longevity. Therefore, correct and comprehensive characterization of the seed protein glycation profiles is absolutely mandatory for understanding the changes in seed metabolism, accompanying stress-related alterations during maturation and storage of seeds. Although proteomics might deliver important functional information, adequate absolute quantification of a broad panel of glycated amino acid adducts is necessary to understand the underlying chemistry of Maillard reaction. However, the related currently existing amino acid analysis workflows suffer from two bottlenecks: on one hand, the majority of glycation adducts are acid- and/or thermally labile, on the other hand-implementation of enzymatic hydrolysis under physiological conditions is restricted by low solubility of seed protein isolates in aqueous buffers.

\subsection{Solubilization and Enzymatic Hydrolysis}

It is well-known, that glycation, i.e., Maillard reaction of proteins, can contribute to seed ageing via protein modification and suppression of cellular antioxidant defense [39]. Although glycation of seed proteins can be addressed by spectrofluorometry [40] and ELISA [22], the state-of-the-art level of analytical techniques assumes LC-MS- or LC-MS/MS-based quantification of multiple specific glycation 
adducts [37].Some AGEs, like CML or pentosidine, can be readily analyzed in different matrices due to efficient solubilization during acid hydrolysis [9]. For some potentially insoluble proteins, like collagen, solubilization can be achieved simultaneously with enzymatic degradation by using such enzymes as collagenase and pepsin $[7,41]$. However, as no ambient protocol for solubilization of seed proteins is reported so far, analysis of chemically labile seed hydroimidazolone AGEs and related structures is still not reported, although it is known, that glycation reduces susceptibility of pear seed protein to enzymatic hydrolysis [42].

The main reason for this is low solubility of seed protein isolates. Indeed, legume seed proteome is strongly dominated by several highly abundant protein families-vicilins, convicilins, 11S globulins (legumins), and 2S albumins (PA1 and PA2) [43], whereas the seed proteome of mature Brassica napus seeds at least for $20 \%$ is represented by napin [44]. Despite potential solubility of the major seed proteins in water, their isolation is usually accompanied with aggregation with minor hydrophobic seed polypeptides and non-protein constituents that result in low solubility of such preparations. In standard proteomic practice, such total protein isolates can be reconstituted in high concentrations of chaotropic reagents (urea, thiourea) of in presence of detergents-conventional (SDS, triton X100) or degradable (e.g., RapiGest or Anionic Acid-Labile Surfactant, AALS) and effectively digested, followed with removal of solubilization agents [3].

In line with these considerations, we decided to transfer the described approach to the exhaustive enzymatic hydrolysis. Accordingly, we achieved complete reconstitution of protein in a small volume of $10 \%(w / v)$ SDS diluted it to accomplish hydrolysis and removed SDS by SPE afterwards. This procedure turned out to be ideally compatible to the enzymatic digestion protocol of the Glomb's group [9]. Indeed, all three enzymes-pronase E, proteinase $\mathrm{K}$ and carboxypeptidase $\mathrm{Y}$, used by these authors, preserved their activity in presence of $0.5 \%$ SDS [45-49]. Thus, reconstitution of protein pellets in $50 \mu \mathrm{L}$ of $10 \%(w / v)$ SDS with subsequent 20-fold dilution with PBS directly brought us to the starting point of this well-established and reliable protocol. Remarkably, ESI-MS analysis of the obtained hydrolysates revealed complete absence of peptides in the mixtures (Figure S4) that indicated completeness of digestion and no necessity in post-hydrolysis filtration step, as it is often done [24].

\subsection{Removal of the Detergent from Hydrolysates}

Selective removal of SDS from the protein hydrolysates was based on the difference in properties of analytes and SDS: even under highly alkali aqueous conditions SDS was completely retained on the reversed phase, whereas amino acids were quantitatively eluted. Thereby, we used two elution steps. The first one, accomplished with the $25 \mathrm{mmol} / \mathrm{L}$ ammonium acetate solution, targeted basic amino acids and adducts, poorly retained on the reversed phase (e.g., hydroimidazolones and, in particular; target compound MG-H1). The second eluent was a base, providing quantitative deprotonation of carboxyl functions and quantitative elution of hydrophobic amino acids, like phenylalanine and tryptophan, which typically retain well on the reversed phase under acidic conditions. This scheme might allow avoiding on-cartridge conversion of alkali-labile imidazolones MG-H3 and Glarg in $N^{\delta}$-(carboxyethyl)-arginine (CEA) and $N^{\delta}$-(carboxymethyl)-arginine (CMA), respectively [27]. The immediate freezing of the eluates after the second elution was, in this context, desired.

\subsection{Quantitative Analysis}

The principle changes, done in the original hydrolysis protocol, ultimately required verification of compatibility with existing quantitative techniques and comprehensive validation of the overall procedure. As the main scope of this study was extending the applicability of existing analytical techniques to new objects and matrices, but not development of new LC-MS or LC-MS/MS protocols, we used here pre-column derivatization with $N^{2}$-(5-fluoro-2,4-dinitrophenyl)-L-valine amide (L-FDVA) with subsequent LC-MS analysis - the method established in our group more than a decade ago [36].Here we just adjusted gradient to the UHPLC technique and optimized the MS method for the LIT-Orbitrap hybrid. 
Surprisingly, our method turned out to be rather sensitive. Thus, despite that a relatively old Orbitrap Elite instrument, operated in the full scan mode, was used here, the limit of detection for MG-H1 (determined with MG-H-d3, spiked to the hydrolysate of glycated BSA, prepared according to our procedure, Table 1) was even lower, than with a triple quadrupole (QqQ)-based multiple reaction monitoring (MRM) method of Hashimoto et al, relying on derivatization with 2,4,6-trinitrobenzene sulfonate [50]. Thereby, an excellent linear dynamic range (LDR), covering four orders of magnitude, could be achieved for this glycation adduct. Most probably, it can be attributed to decrease of matrix-related suppression effects [51] for cationic derivatives after the SPE procedure, of even signal enhancement, as could be seen in model experiments with amino acid mixtures (Figure S5) and glycated BSA (Figures S7 and S8). The enhancement effect can be, at least partly, underlied by formation of ammonia adducts in eluates and, therefore, lower losses of analytes by adsorption on the walls of polypropylene tubes. Of course, the method sensitivities can be essentially increased by switch to well-established MRM-based workflows [52,53]. Establishing a new MS/MS-based protocol was, however, behind the scope of this study. Not less importantly, one needs to take into account that, due to high contents of ammonium acetate in samples, our workflow can potentially affect analyte retention in ion pair chromatography. Indeed, due to a relatively low flow rate, a local drop of the ion pair reagent concentration in the eluent can occur, and retention time shifts can be detected (personal unpublished observation). Thereby, higher injection volumes (as, for example, $100 \mu \mathrm{L}$ used here) would favor these effects. Indeed, acetate might form a strong ion pair with trifluoroacetic or heptafluorobutyric acids and change retention times and peak symmetry. Clearing this issue must also be also the matter of future studies. As reduction of injection volumes seems to be not possible in terms of sensitivity, an additional SPE step might be considered.

The most remarkable feature of our procedure was its high intra- and inter-day precision. Indeed, the overall relative standard deviation (RSD\%) of hydrolysis and SPE did not exceed $8 \%$, whereas the precision of the derivatization procedure and the measurement itself was within $2 \%$, that is relatively low for LC-MS-based quantification [52]. Hence, the digestion/pre-cleaning method block can be incorporated in any MS-based protocol, independently from employed derivatization and/or chromatographic system. Moreover, it can be incorporated in functional physiological assays of Maillard reaction products, and provide thereby direct access to structure-response relationships.

\section{Materials and Methods}

\subsection{Reagents and Plant Material}

Unless stated otherwise, materials were obtained from the following manufacturers. Carl Roth GmbH \& Co. (Karlsruhe, Germany): ammonia solution (25\%); ethanol ( $\geq 99.8 \%)$, sodium dodecyl sulfate (SDS) (>99\%), sodium chloride (p.a.), sodium phosphate dibasic dehydrate (p.a.); PanReac AppliChem (Darmstadt, Germany): acrylamide (2K Standard Grade), glycerol (ACS grade); AMRESCO LLC (Fountain Parkway Solon, OH, USA): ammonium persulfate (ACS grade), glycine (biotechnology grade), $N, N^{\prime}$-methylene-bis-acrylamide (ultra pure grade), tris(hydroxymethyl)aminomethane (tris, ultra pure grade), urea (ultra pure grade); Component-Reactiv (Moscow, Russia): phosphoric acid (p.a.); Iris Biotech GmbH (Marktredwitz, Germany): methylglyoxal-derived hydroimidazolone 1 (MG-H1, p.a.) and MG-H1-d3 (p.a.); Merck KGaA (Darmstadt, Germany): potassium chloride (p.a.), sodium phosphate monobasic monohydrate (p.a.); Reachem (Moscow, Russia): hydrochloric acid (p.a.), isopropanol (reagent grade); SERVA Electrophoresis GmbH (Heidelberg, Germany): Coomassie Brilliant Blue G-250, 2-mercaptoethanol (research grade); Thermo Fisher Scientific (Waltham, USA): Pierce $^{\mathrm{TM}}$ Unstained Protein Molecular Weight Marker \#26610 (14.4-116.0 kDa), PageRuller ${ }^{\mathrm{TM}}$ Plus Prestained Protein Ladder \#26620 (10-250 kDa); Vekton (St. Petersburg, Russia): acetonitrile (HPLC grade), conc. $\mathrm{HCl}$ (puriss). All other chemicals were purchased from Sigma-Aldrich Chemie $\mathrm{GmbH}$ (Taufkirchen, Germany). Water was purified in house on a water conditioning and purification system Millipore Milli-Q Gradient A10 system (resistance $18 \mathrm{~m} \Omega / \mathrm{cm}$, Merck Millipore, Darmstadt, Germany). 
Pea seeds of the cultivar Millennium were obtained from the Research and Practical Center of National Academy of Science of the Republic of Belarus for Arable Farming (Zhodino, Belarus, harvested in the year 2015 and stored at $\left.18{ }^{\circ} \mathrm{C}\right)$. Oilseed rape seeds of the cultivar Oredezh-2 (K-4917) from the State research enterprise Leningrad Research institute for Applied Agricultural Science "Belogorka" Russian Academy of Agricultural Science were provided by the Federal Research Center "The N.I. Vavilov All-Russian Institute of Plant Genetic Resources" (VIR). Rape seeds were harvested in the year 2008 and 2015 and stored at $18{ }^{\circ} \mathrm{C}$.

\subsection{Glycation of Bovine Serum Albumin (BSA)}

Glycation of BSA was accomplished by a well-established procedure [54], later modified by Greifenhagen et al [55] and slightly changed here. In detail, $20 \mathrm{mg}$ of BSA in $1 \mathrm{~mL}$ of $100 \mathrm{mmol} / \mathrm{L}$ sodium phosphate buffer (pH 7.4), containing $18 \mu \mathrm{mol} / \mathrm{L} \mathrm{FeSO}_{4}$ and $250 \mathrm{mmol} / \mathrm{L}$ D-glucose, was filtrated with a $0.22 \mu \mathrm{m}$ filter and incubated at $55^{\circ} \mathrm{C}$ during 7 days under continuous shaking ( $450 \mathrm{rpm}$ ) in safe-lock $1.5 \mathrm{~mL}$ polypropylene tubes. After the completion of the incubations, the buffer was changed to phosphate buffered saline (PBS) by ultrafiltration in Vivaspin filter devices equipped with polyethersulfone (PES) membrane with 3000 MW cut-off (Sartorius, Göttingen, Germany). Afterwards, protein concentration was determined by 2D-Quant kit (GE Healthcare, Taufkirchen, Germany) as described by Matamoros and co-workers [21].

\subsection{Ageing of Pea and Oilseed Rape Seeds}

To establish the model of natural ageing, rape seeds were stored for nine years at $18^{\circ} \mathrm{C}$ in the dark. To establish the model of accelerated ageing, pea seeds were incubated in a desiccator at $45^{\circ} \mathrm{C}$ above a saturated $\mathrm{KCl}$ solution ( $86 \%$ relative humidity). It resulted in increase of the seed water content from $9 \%$ to $18 \%(w / w)$. The seeds were removed from the desiccator on the fifth day, dried to the initial water content of $9 \%(w / w)$, and stored at $4{ }^{\circ} \mathrm{C}$ in closed containers.

\subsection{Protein Isolation}

Pea and oil seed rape seeds (10 and 35 per biological replicate, for pea and oilseed rape, respectively, $n=3$ ) were frozen in liquid nitrogen and ground in a Mixer Mill MM 400 ball mill with a $\varnothing 20 \mathrm{~mm}$ stainless steel ball (Retsch, Haan, Germany) at a vibration frequency of $30 \mathrm{~Hz}$ for $2 \times 1 \mathrm{~min}$. The obtained frozen powder (approximately $50 \mathrm{mg}$ per replicate) was transferred to $2 \mathrm{~mL}$ safe-lock polypropylene tubes and stored at $-80{ }^{\circ} \mathrm{C}$ prior to protein isolation, which relied on the phenol extraction method, as described by Frolov and co-workers [56] with some modifications. Briefly, the tubes with seed material were placed on ice, and $650 \mu \mathrm{L}$ of cold $\left(4^{\circ} \mathrm{C}\right)$ phenol extraction buffer $(0.7 \mathrm{~mol} / \mathrm{L}$ sucrose, $0.1 \mathrm{~mol} / \mathrm{L} \mathrm{KCl}, 5 \mathrm{mmol} / \mathrm{L}$ ethylenediaminetetraacetic acid (EDTA), $2 \%(v / v)$ mercaptoethanol and $1 \mathrm{mmol} / \mathrm{L}$ phenylmethylsulfonyl fluoride (PMSF) in $0.5 \mathrm{~mol} / \mathrm{L}$ tris- $\mathrm{HCl}$ buffer, $\mathrm{pH} 7.5$ ) were added. The suspensions were vortexed for $30 \mathrm{~s}$, and $650 \mu \mathrm{L}$ of cold phenol $\left(4^{\circ} \mathrm{C}\right)$ saturated with $0.5 \mathrm{~mol} / \mathrm{L}$ tris-HCl buffer ( $\mathrm{pH} 7.5$ ) were added. Afterwards, the samples were extracted for $30 \mathrm{~min}$ at $900 \mathrm{rpm}$ $\left(4{ }^{\circ} \mathrm{C}\right)$ and centrifuged $\left(5000 \times g, 30 \mathrm{~min}, 4^{\circ} \mathrm{C}\right)$. The phenolic (upper) phases were transferred to new $1.5 \mathrm{~mL}$ polypropylene tubes and washed two times with equal volumes of the phenol extraction buffer (with vortexing $30 \mathrm{~s}$, shaking for $30 \mathrm{~min}$ at $900 \mathrm{rpm}$ at $4{ }^{\circ} \mathrm{C}$ and centrifugation at $5000 \times \mathrm{g}$ for $15 \mathrm{~min}$ at $4{ }^{\circ} \mathrm{C}$ after each buffer addition). Finally, the supernatants were collected in $1.5 \mathrm{~mL}$ polypropylene safe-lock tubes, and proteins were precipitated by a five-fold volume of cold $0.1 \mathrm{~mol} / \mathrm{L}$ ammonium acetate in methanol, followed with storage at $-20^{\circ} \mathrm{C}$ overnight. After this, the proteins were pelleted by centrifugation $\left(10 \mathrm{~min}, 5000 \times \mathrm{g}, 4^{\circ} \mathrm{C}\right)$. The pellets were washed twice by re-suspending in two volumes of methanol (compared to the phenol phase volume), and twice-in the same volume of acetone (both at $4{ }^{\circ} \mathrm{C}$ ), followed with centrifugation $\left(5000 \times \mathrm{g}, 10 \mathrm{~min}, 4{ }^{\circ} \mathrm{C}\right)$. The final pellets were dried under air in a hood for $1 \mathrm{~h}$, re-dissolved in $100 \mu \mathrm{L}$ of $10 \%(w / v)$ SDS, and protein contents were determined by 2-D Quant Kit. 


\subsection{SDS-PAGE}

Polyacrylamide gel electrophoresis in sodium dodecyl sulfate (SDS-PAGE) was performed as described by Greifenhagen et al. [57] with minor modifications. In detail, separations were performed with a $12 \%$ resolving and a $6 \%$ stacking gel $(\mathrm{T}=12 \%, \mathrm{C}=2.65 \%)$. The aliquots of protein or hydrolysate samples $(10 \mu \mathrm{g})$, were freeze-dried under reduced pressure and reconstituted in $20 \mu \mathrm{L}$ of sample buffer, containing $0.05 \%(w / v)$ bromophenol blue, 20\% (v/v) glycerol, 2\% $(w / v)$ SDS, $5 \%(v / v) \beta$-mercaptoethanol in $62.5 \mathrm{mmol} / \mathrm{L}$ Tris- $\mathrm{HCl}$ ( $\mathrm{pH}$ 6.8). On each lane, $10 \mu \mathrm{L}$ of dissolved sample (5 $\mu \mathrm{g}$ each) were loaded. Aliquots of enzymatic hydrolysates, corresponding to $5 \mu \mathrm{g}$, were completely dried under reduced pressure, reconstituted in $10 \mu \mathrm{L}$ of the same buffer and completely loaded on each lane. The molecular weights of individual proteins were assigned by a molecular weight standard mix, run on the same gel. After completion of separation ( $45 \mathrm{~min}$ at $200 \mathrm{~V})$, gels were stained with Coomassie Brilliant Blue G-250 for $1 \mathrm{~h}$. Average densities across individual lanes (expressed in arbitrary units) were determined by ChemiDoc XRS imaging system controlled by Quantity One ${ }^{\circledR}$ 1-D analysis software (Bio-Rad Laboratories Ltd., Moscow, Russia). For calculation of relative standard deviations (RSDs), the densities of individual lines were normalized to the gel average value.

\subsection{Exhaustive Enzymatic Hydrolysis}

Enzymatic hydrolysis was performed with $0.3-3.7 \mathrm{mg}$ of BSA, $1 \mathrm{mg}$ of oilseed rape and $0.3 \mathrm{mg}$ of pea protein. The appropriate volumes of protein solutions in 10\% $(w / v)$ SDS (not exceeding $50 \mu \mathrm{L}$ ) were transferred in a $2 \mathrm{~mL}$ safe-lock polypropylene tube and adjusted to $1 \mathrm{~mL}$ with phosphate buffered saline (PBS, $137 \mathrm{mmol} / \mathrm{L} \mathrm{NaCl}, 2.7 \mathrm{mmol} / \mathrm{L} \mathrm{KCl}, 10 \mathrm{mmol} / \mathrm{L} \mathrm{Na} 2 \mathrm{HPO}_{4}, 1.8 \mathrm{mmol} / \mathrm{L} \mathrm{KH}_{2} \mathrm{PO}_{4}, \mathrm{pH}$ 7.4). The resulted mixtures were supplemented with internal standard (560 pmol of MG-H-d3), $3 \mu \mathrm{L}$ of $1 \mathrm{~mol} / \mathrm{L} \mathrm{CaCl}_{2}$ solution and a small crystal of thymol. Then, the following enzymes were added sequentially: 1.2 units of pronase $\mathrm{E}$ (twice), 0.195 units of proteinase $\mathrm{K}$ and 0.05 units of carboxypeptidase $\mathrm{Y}$. Thereby, all incubations were performed for $24 \mathrm{~h}$ at $37{ }^{\circ} \mathrm{C}$ (incubation with carboxypeptidase $\mathrm{Y}$ was performed at $25^{\circ} \mathrm{C}$ ) under continuous shaking at $450 \mathrm{rpm}$ in the dark.

\subsection{Solid Phase Extraction (SPE)}

Solid phase extraction (SPE) was done on reversed phase using CHROMABOND ec (end-capped) C18 cartridges and vacuum manifold (Macherey Nagel, Düren, Germany, operated under the pressure of 850 mbar. The cartridges were pre-conditioned with $6 \mathrm{~mL}$ of methanol, equilibrated with $6 \mathrm{~mL}$ of water, before the hydrolysates $(1 \mathrm{~mL}$ each) were applied. The fraction, containing amino acids was sequentially eluted with $6 \mathrm{~mL}$ of $25 \mathrm{mmol} / \mathrm{L}$ aq. ammonium acetate and $6 \mathrm{~mL}$ of $100 \mathrm{mmol} / \mathrm{L}$ aq. ammonia. The flow-through and both eluate fractions were saved in one 15-mL polypropylene tube and freeze-dried. The residues were sequentially reconstituted in two $0.5-\mathrm{mL}$ portions of $20 \%$ $(v / v)$ aq. acetonitrile, transferred to a $1.5-\mathrm{mL}$ polypropylene tube, freeze-dried and stored at $-20^{\circ} \mathrm{C}$ before analysis.

\subsection{Derivatization}

Prior to analysis, hydrolysates were reconstituted in $30 \mu \mathrm{L}$ of $20 \%(v / v)$ acetonitrile and derivatized with $N^{2}$-(5-fluoro-2,4-dinitrophenyl)-L-valine amide (L-FDVA) as described by Ehrlich and co-workers [36] with some modifications. In detail, $20 \mu \mathrm{L}$ of hydrolysate aliquots were supplemented with $7 \mu \mathrm{L}$ of water and $\mathrm{pH}$ was adjusted to 8.0 with $1 \mathrm{~mol} / \mathrm{L} \mathrm{NaHCO}_{3}$ using indicator paper (typically $4-20 \mu \mathrm{L}$ of $\mathrm{NaHCO}_{3}$ were required). Afterwards, $32 \mu \mathrm{L}$ of $36.7 \mathrm{mmol} / \mathrm{L}$ $N^{2}$-(5-fluoro-2,4-dinitrophenyl)-L-valine amide (L-FDVA) acetone solution were added, and reactions were performed during $90 \mathrm{~min}$ at $40{ }^{\circ} \mathrm{C}$ under continuous shaking ( $350 \mathrm{rpm}$ ), before the reactions were stopped by addition of $25 \mu \mathrm{L}$ of $1 \mathrm{~mol} / \mathrm{L} \mathrm{HCl}$. After the change of solution color to yellow, $50 \mu \mathrm{L}$ of acetonitrile and $96 \mu \mathrm{L}$ of water were added, and the samples were intensively vortexed. Finally, $500 \mu \mathrm{L}$ 
$0.1 \%(v / v)$ formic acid were added, the samples were centrifuged $(15,000 \times g, 5 \mathrm{~min}$, room temperature), and the supernatants were transferred to the inserts of the vials for HPLC.

\subsection{RP-UHPLC-ESI-LIT-Orbitrap-MS Analysis}

For analysis of the L-FDVA derivatives in hydrolyzates, $100 \mu \mathrm{L}$ of sample were loaded on a reversed phase Hypersil GOLD aQ column $(100 \times 1 \mathrm{~mm}, 1.9 \mu \mathrm{m}$ particle size), installed on a Dionex Ultimate 3000 UHPLC System (Thermo fisher Scientific, Bremen, Germany). The separations were performed at the flow rate of $150 \mu \mathrm{L} / \mathrm{min}$, at $40^{\circ} \mathrm{C}$ in a linear gradient mode, with eluents $\mathrm{A}$ and $\mathrm{B}$ being water and acetonitrile, both containing $0.1 \%(v / v)$ formic acid. After a two-minute isocratic step at $5 \%$ eluent $\mathrm{B}$, amino acid derivatives were separated in the sequential gradients to $20 \%, 33 \%$ and $42 \%$ eluent $B$ in 1, 7, and $4 \mathrm{~min}$, respectively. After a second isocratic segment (4 min at $42 \%$ eluent $B$ ) a further gradient to $70 \%$ eluent $B$ was run in $3 \mathrm{~min}$. The column effluents were transferred on-line into a hybrid LTQ-Orbitrap Elite mass spectrometer (Thermo Fisher Scientific, Darmstadt, Germany), equipped with a heated electrospray ionization (HESI) source and operated in the positive ion mode, under the settings, listed in Table S4. Annotation of analytes relied on $m / z, t_{R}$ and MS/MS data. Quantitative analysis relied on the stable isotope dilution strategy and integration of corresponding extracted ion chromatograms (XICs) at specific $t_{R}$. Peak integration was performed in LCquan ${ }^{\mathrm{TM}} 2.8$ software (Thermo Fisher Scientific, Berlin, Germany).

\subsection{Method Validation}

In terms of the method validation, limits of detection and quantification (LOD and LOQ, respectively), linear dynamic range (LDR), accuracy, stability, as well as intra- and inter-day precision for hydrolysis, derivatization, and chromatographic analysis, were determined. The analysis of hydrolysis precision relied on spiking of $500 \mu \mathrm{g}(n=12,4$ replicates per day) glycated BSA with the internal standard (MG-H1-d3, $0.5 \mu \mathrm{mol} / \mathrm{L}$ ) prior to hydrolysis. The other precision tests and stability assay were performed with $300 \mu \mathrm{g}$ aliquots of BSA ( $n=4$ per day, totally 12 assays/test) and $0.25 \mu \mathrm{mol} / \mathrm{L}$ spiked standard. For each precision test, an appropriate pooled sample was prepared, aliquoted and frozen. Four aliquots were thawed and analyzed on each of three consecutive days, and intra-/inter-day precision was determined. For the assessment of analyte stability, the same samples were analyzed for three constitutive days.

\subsection{Cell Culture}

Human mock-transfected neuroblastoma SH-SY5Y cells were cultured in a high glucose $(4.5 \mathrm{~g} / \mathrm{L})$ Dulbecco's modified Eagle's medium (DMEM) with glutamax supplied with $10 \%$ heat-inactivated fetal calf serum, $1 \%$ penicillin and streptomycin, $1 \%$ minimal essential media vitamin, $1 \%$ nonessential amino acid, $1 \%$ sodium pyruvate, and $0.66 \%$ hygromycin $\mathrm{B}$ at $37{ }^{\circ} \mathrm{C}, 5 \% \mathrm{CO}_{2}, 95 \%$ air. Cells were passaged by trypsinization. The procedure was conducted by rinsing the cells with PBS at $37^{\circ} \mathrm{C}$ before detaching cells by $3 \mathrm{~mL}$ of trypsin/EDTA solution $(0.25 \% / 0.2 \%)$ at $37^{\circ} \mathrm{C}$ for $2 \mathrm{~min}$. Cell detachment was stopped by adding of $10 \mathrm{~mL}$ of full medium. After that cells were collected by centrifugation (1500 rpm, $5 \mathrm{~min}, 25^{\circ} \mathrm{C}$ ) and re-suspended in fresh medium. The cell number was determined using an automatic cell counter. For 3-(4,5-dimethylthiazol-2-yl)-2,5-diphenyltetrazolium bromide (MTT) assay, cell confluence of $\geq 80 \%$ and passages from 4 to 10 were used.

\subsection{Analysis of Cell Viability by MTT Assay}

The viability of human neuroblastoma cells SH-SY5Y was determined by a quantitative colorimetric assay with 3-(4,5-dimethyl thiazol-2-yl)-2,5-diphenyltetrazolium bromide (MTT) according to the method of Mosmann [58] with modifications. The cells were seeded in 96-well plates at a density of 50,000 cells $/ 100 \mu \mathrm{L}$ per well and were allowed to grow for $48 \mathrm{~h}$ before treatment. Then the medium was changed, and the cells were stimulated with sterile filtrated protein hydrolysates for $24 \mathrm{~h}$ at $37^{\circ} \mathrm{C}$. Concentration of tested substances ranged from 0.05 to $0.4 \mathrm{mg} / \mathrm{mL}$ for the glycated hydrolyzed BSA and 
from 0.075 to $0.3 \mathrm{mg} / \mathrm{mL}$ for the hydrolyzed pea seed protein, dissolved in culture medium. Control cells were incubated with medium without further supplements. The cells treated with $10 \%(v / v)$ DMSO served as positive control. After stimulation, $20 \mu \mathrm{L}$ of MTT solution $(5 \mathrm{mg} / \mathrm{mL}$ in PBS, $\mathrm{pH} 7.3)$ was added. Then cells were incubated with MTT for $2 \mathrm{~h}$ at $37^{\circ} \mathrm{C}$. After removal of the supernatant, formazan crystals were dissolved by adding of $100 \mu \mathrm{L}$ of solubilization solution $(20 \% w / v$ SDS, $0.1 \mathrm{~N}$ $\mathrm{HCl} / \mathrm{DMF}(1: 1))$. The cells with the solution were then kept in a water bath $\left(37^{\circ} \mathrm{C}\right)$ overnight. Then after shaking for $10 \mathrm{~min}$, the absorbance was detected at a wavelength of $570 \mathrm{~nm}$. The cell viability of stimulated cells was expressed as percentage cell viability in comparison to the negative control (culture medium).

\section{Conclusions}

Here we report a reliable procedure, based on complete solubilization of seed protein isolates of any origin and exhaustive enzymatic hydrolysis of glycated proteins. Thus, we overcome here the main limitation of enzymatic hydrolysis, i.e., its poor applicability to proteins, insoluble in aqueous buffers. The proposed sample preparation protocol can be efficiently coupled to the state-of-the-art LC-MS-based quantification techniques and biological assays, prospectively addressing physiological effects of glycation products, formed in seeds during ageing or/and under environmental stress. Obviously, in the future, this strategy will be easily extended to a wide panel of AGEs routinely identified by Glomb's group (which hydrolysis procedure was used as a starting point here). Moreover, to our mind, it can be implemented in any other digestion protocols, also combined with untargeted LC-MS workflows. Finally, it might be extended to non-seed and even non-plant objects. We are convinced that in combination with rapidly developing bottom-up proteomic techniques, our method will give access to the mechanisms and pathways of the Maillard reaction in new objects and matrices, which were not available for analysis earlier.

Supplementary Materials: Supplementary materials can be found at http:/www.mdpi.com/1422-0067/20/15/ 3659/s1.

Author Contributions: K.A. and A.F. wrote the draft; M.V., A.S. and T.M. performed optimization of protein solubilization strategy, S.P.E. methodology and chromatographic conditions; K.A., A.S. and T.M. established and validated LC-MS method; M.V., M.-L.H. and S.G.-R. performed cytotoxicity experiments; T.L. and E.L. prepared and characterized protein isolates; M.B. performed accelerated ageing experiments; S.M. and G.S. supervised the work with seeds and contributed in the final text of the manuscript; M.P. supervised biological experiments and contributed in the final text of the manuscript; A.F. supervised the whole work and contributed in the final text of the manuscript.

Funding: This research was funded by the Russian Science Foundation (project number 17-16-01042).

Conflicts of Interest: The authors declare no conflict of interest.

\section{Abbreviations}

$\begin{array}{ll}\text { AALS } & \text { anionic acid-labile surfactant } \\ \text { AGEs } & \text { advanced glycation end products } \\ \text { average value } \\ \text { BSA } & \text { bovine serum albumin } \\ \text { CEA } & N^{\delta} \text {-(carboxyethyl)arginine } \\ \text { CMA } & N^{\delta} \text {-(carboxymethyl)arginine } \\ \text { CML } & N^{\varepsilon} \text {-(carboxymethyl)lysine } \\ \text { DMEM } & \text { Dulbecco's modified Eagle's medium } \\ \text { DMF } & \text { N,N-dimethylformamide } \\ \text { DMSO } & \text { dimethyl sulfoxide } \\ \text { EDTA } & \text { ethylenediaminetetraacetic acid } \\ \text { ESI } & \text { electrospray ionization } \\ \text { FIA-HR-MS } & \text { flow injection analysis coupled on-line with high-resolution mass spectrometry } \\ \text { HESI } & \text { heated electrospray ionization } \\ \text { LDR } & \text { linear dynamic range } \\ \text { L-FDVA } & N^{2} \text {-(5-fluoro-2,4-dinitrophenyl)-L-valine amide }\end{array}$




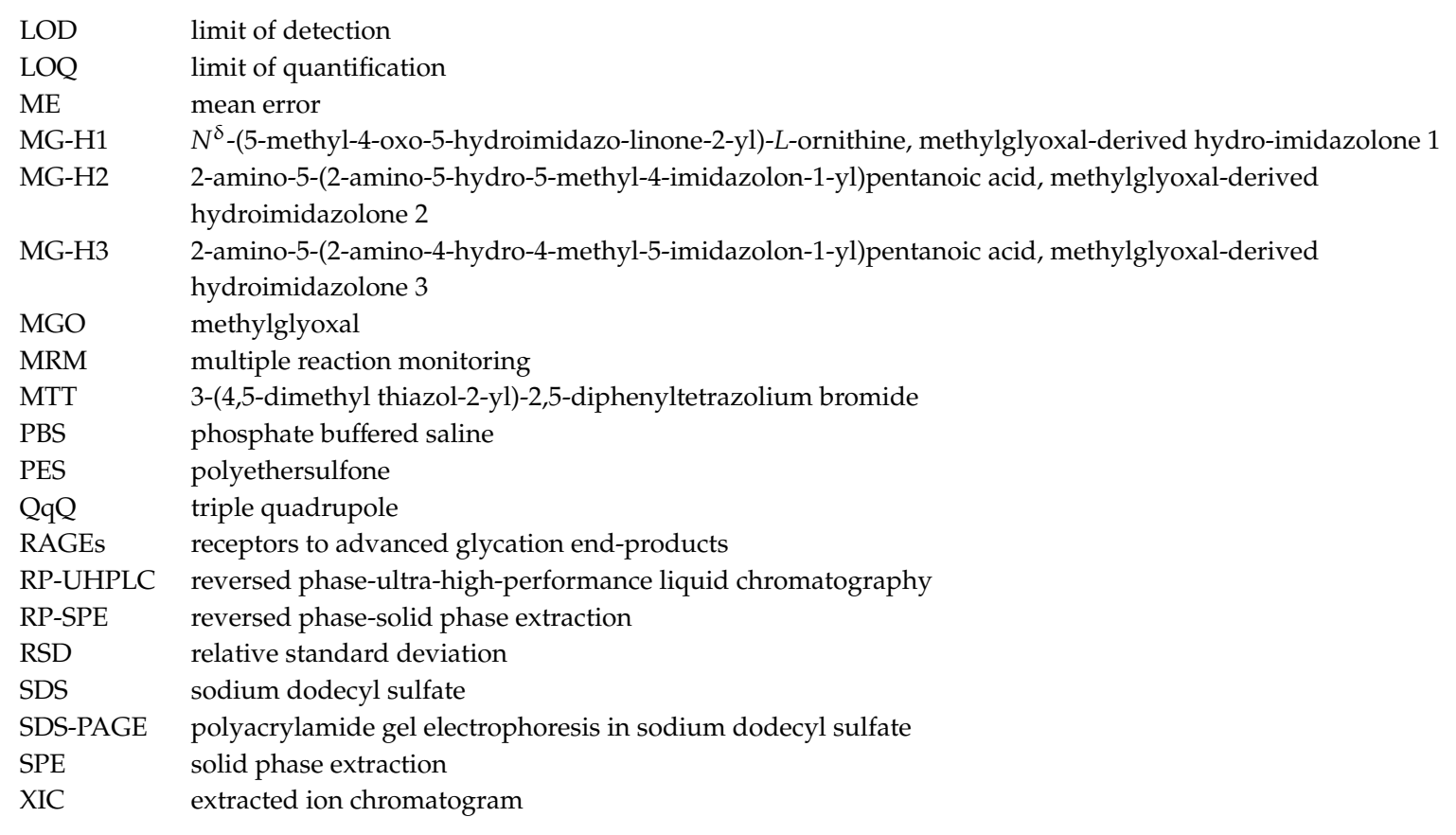

\section{References}

1. Food and Agriculture Organization of the United Nations. The State of Food Security and Nutrition in the World. Building Climate Resilience for Food Security and Nutrition; FAO: Rome, Italy, 2018; p. 108.

2. Bradford, K.J.; Dahal, P.; van Asbrouck, J.; Kunusoth, K.; Bello, P.; Thompson, J.; Wu, F. The dry chain: Reducing postharvest losses and improving food safety in humid climates. Trends Food Sci. Technol. 2018, 71, 84-93. [CrossRef]

3. Frolov, A.; Mamontova, T.; Ihling, C.; Lukasheva, E.; Bankin, M.; Chantseva, V.; Vikhnina, M.; Soboleva, A.; Shumilina, J.; Mavropolo-Stolyarenko, G.; et al. Mining seed proteome: From protein dynamics to modification profiles. Biol. Commun. 2018, 63, 43-58. [CrossRef]

4. Murthy, U.M.N.; Kumar, P.P.; Sun, W.Q. Mechanisms of seed ageing under different storage conditions for Vigna radiata (L.) Wilczek: Lipid peroxidation, sugar hydrolysis, Maillard reactions and their relationship to glass state transition. J. Exp. Bot. 2003, 54, 1057-1067. [CrossRef] [PubMed]

5. Hampton, J.G.; TeKrony, D.M. Handbook of Vigour Test. Method; International Seed Testing Association: Zurich, Switzerland, 1995.

6. Milkovska-Stamenova, S.; Schmidt, R.; Frolov, A.; Birkemeyer, C. GC-MS Method for the Quantitation of Carbohydrate Intermediates in Glycation Systems. J. Agric. Food Chem. 2015, 63, 5911-5919. [CrossRef] [PubMed]

7. Soboleva, A.; Vikhnina, M.; Grishina, T.; Frolov, A. Probing Protein Glycation by Chromatography and Mass Spectrometry: Analysis of Glycation Adducts. Int. J. Mol. Sci. 2017, 18. [CrossRef] [PubMed]

8. Singh, V.P.; Bali, A.; Singh, N.; Jaggi, A.S. Advanced glycation end products and diabetic complications. Korean J. Physiol. Pharm. 2014, 18, 14. [CrossRef] [PubMed]

9. Smuda, M.; Henning, C.; Raghavan, C.T.; Johar, K.; Vasavada, A.R.; Nagaraj, R.H.; Glomb, M.A. Comprehensive analysis of maillard protein modifications in human lenses: Effect of age and cataract. Biochemistry 2015, 54, 2500-2507. [CrossRef] [PubMed]

10. Hellwig, M.; Henle, T. Baking, ageing, diabetes: A short history of the Maillard reaction. Angew. Chem. Int. Ed. Engl. 2014, 53, 10316-10329. [CrossRef] [PubMed]

11. Monnier, V.M.; Sun, W.; Gao, X.; Sell, D.R.; Cleary, P.A.; Lachin, J.M.; Genuth, S. Skin collagen advanced glycation endproducts (AGEs) and the long-term progression of sub-clinical cardiovascular disease in type 1 diabetes. Cardiovasc. Diabetol. 2015, 14, 118. [CrossRef]

12. Huttunen, H.J.; Fages, C.; Rauvala, H. Receptor for advanced glycation end products (RAGE)-mediated neurite outgrowth and activation of NF-kappaB require the cytoplasmic domain of the receptor but different downstream signaling pathways. J. Biol. Chem. 1999, 274, 19919-19924. [CrossRef] 
13. Skrha, J. Pathogenesis of angiopathy in diabetes. Acta Diabetol. 2003, 40 (Suppl. 2), S324-S329. [CrossRef] [PubMed]

14. Daulatzai, M.A. Fundamental role of pan-inflammation and oxidative-nitrosative pathways in neuropathogenesis of Alzheimer's disease in focal cerebral ischemic rats. Am. J. Neurodegener. Dis. 2016, 5, 102-130. [PubMed]

15. Chen, H.; O’Reilly, E.J.; Schwarzschild, M.A.; Ascherio, A. Peripheral inflammatory biomarkers and risk of Parkinson's disease. Am. J. Epidemiol. 2008, 167, 90-95. [CrossRef] [PubMed]

16. Wada, R.; Yagihashi, S. Role of advanced glycation end products and their receptors in development of diabetic neuropathy. Ann. N. Y. Acad. Sci. 2005, 1043, 598-604. [CrossRef] [PubMed]

17. Bechtold, U.; Rabbani, N.; Mullineaux, P.M.; Thornalley, P.J. Quantitative measurement of specific biomarkers for protein oxidation, nitration and glycation in Arabidopsis leaves. Plant. J. 2009, 59, 661-671. [CrossRef] [PubMed]

18. Bilova, T.; Lukasheva, E.; Brauch, D.; Greifenhagen, U.; Paudel, G.; Tarakhovskaya, E.; Frolova, N.; Mittasch, J.; Balcke, G.U.; Tissier, A.; et al. A Snapshot of the plant glycated proteome: Structural, functional, and mechanistic aspects. J. Biol. Chem. 2016, 291, 7621-7636. [CrossRef] [PubMed]

19. Paudel, G.; Bilova, T.; Schmidt, R.; Greifenhagen, U.; Berger, R.; Tarakhovskaya, E.; Stöckhardt, S.; Balcke, G.U.; Humbeck, K.; Brandt, W.; et al. Changes in Arabidopsis thaliana advanced glycated proteome induced by the polyethylene glycol-related osmotic stress. J. Exp. Bot. 2016, 67, 6283-6295. [CrossRef] [PubMed]

20. Bilova, T.; Paudel, G.; Shilyaev, N.; Schmidt, R.; Brauch, D.; Tarakhovskaya, E.; Milrud, S.; Smolikova, G.; Tissier, A.; Vogt, T.; et al. Global proteomic analysis of advanced glycation end products in the arabidopsis proteome provides evidence for age-related glycation hotspots. J. Biol. Chem. 2017, 292, 15758-15776. [CrossRef]

21. Matamoros, M.A.; Kim, A.; Penuelas, M.; Ihling, C.; Griesser, E.; Hoffmann, R.; Fedorova, M.; Frolov, A.; Becana, M. Protein Carbonylation and Glycation in Legume Nodules. Plant Physiol. 2018, 177, 1510-1528. [CrossRef]

22. Castellión, M.; Matiacevich, S.; Buera, P.; Maldonado, S. Protein deterioration and longevity of quinoa seeds during long-term storage. Food Chem. 2010, 121, 952-958. [CrossRef]

23. Henle, T.; Walter, A.W.; Haessner, R.; Klostermeyer, H. Detection and identification of a protein-bound imidazolone resulting from the reaction of arginine residues and methylglyoxal. Z. Lebensm. Unters. Forsch. 1994, 199, 55-58. [CrossRef]

24. Ahmed, N.; Argirov, O.K.; Minhas, H.S.; Cordeiro, C.A.; Thornalley, P.J. Assay of advanced glycation endproducts (AGEs): Surveying AGEs by chromatographic assay with derivatization by 6-aminoquinolyl- $N$-hydroxysuccinimidyl-carbamate and application to Nepsilon-carboxymethyl-lysine- and Nepsilon-(1-carboxyethyl)lysine-modified albumin. Biochem. J. 2002, 364, 1-14. [PubMed]

25. Klopfer, A.; Spanneberg, R.; Glomb, M.A. Formation of arginine modifications in a model system of N $\alpha$-tert-butoxycarbonyl (Boc)-arginine with methylglyoxal. J. Agric. Food Chem. 2011, 59, $394-401$. [CrossRef] [PubMed]

26. Frolov, A.; Schmidt, R.; Spiller, S.; Greifenhagen, U.; Hoffmann, R. Arginine-derived advanced glycation end products generated in peptide-glucose mixtures during boiling. J. Agric. Food Chem. 2014, 62, 3626-3635. [CrossRef] [PubMed]

27. Schmidt, R.; Bohme, D.; Singer, D.; Frolov, A. Specific tandem mass spectrometric detection of AGE-modified arginine residues in peptides. J. Mass Spectrom. 2015, 50, 613-624. [CrossRef] [PubMed]

28. Shipanova, I.N.; Glomb, M.A.; Nagaraj, R.H. Protein modification by methylglyoxal: Chemical nature and synthetic mechanism of a major fluorescent adduct. Arch. Biochem. Biophys. 1997, 344, 29-36. [CrossRef] [PubMed]

29. Oya, T.; Hattori, N.; Mizuno, Y.; Miyata, S.; Maeda, S.; Osawa, T.; Uchida, K. Methylglyoxal modification of protein. Chemical and immunochemical characterization of methylglyoxal-arginine adducts. J. Biol. Chem. 1999, 274, 18492-18502. [CrossRef] [PubMed]

30. Ahmed, N.; Thornalley, P.J. Chromatographic assay of glycation adducts in human serum albumin glycated in vitro by derivatization with 6-aminoquinolyl- $N$-hydroxysuccinimidyl-carbamate and intrinsic fluorescence. Biochem. J. 2002, 364, 15-24. [CrossRef] 
31. Thornalley, P.J.; Battah, S.; Ahmed, N.; Karachalias, N.; Agalou, S.; Babaei-Jadidi, R.; Dawnay, A. Quantitative screening of advanced glycation endproducts in cellular and extracellular proteins by tandem mass spectrometry. Biochem. J. 2003, 375, 581-592. [CrossRef]

32. Henning, C.; Smuda, M.; Girndt, M.; Ulrich, C.; Glomb, M.A. Molecular basis of maillard amide-advanced glycation end product (AGE) formation in vivo. J. Biol. Chem. 2011, 286, 44350-44356. [CrossRef]

33. Chevalier, F.; Chobert, J.M.; Dalgalarrondo, M.; Haertlé, T. Characterization of the Maillard reaction products of $\beta$-lactoglobulin glucosylated in mild conditions. J. Food Biochem. 2001, 25, 33-55. [CrossRef]

34. Yamanaka, M.; Shirakawa, J.; Ohno, R.; Shinagawa, M.; Hatano, K.; Sugawa, H.; Arakawa, S.; Furusawa, C.; Nagai, M.; Nagai, R. Soft-shelled turtle eggs inhibit the formation of AGEs in the serum and skin of diabetic rats. J. Clin. Biochem. Nutr. 2016, 58, 130-134. [CrossRef] [PubMed]

35. Jost, T.; Zipprich, A.; Glomb, M.A. Analysis of Advanced Glycation Endproducts in Rat Tail Collagen and Correlation to Tendon Stiffening. J. Agric. Food Chem. 2018, 66, 3957-3965. [CrossRef] [PubMed]

36. Ehrlich, H.; Hanke, T.; Frolov, A.; Langrock, T.; Hoffmann, R.; Fischer, C.; Schwarzenbolz, U.; Henle, T.; Born, R.; Worch, H. Modification of collagen in vitro with respect to formation of $\mathrm{N}^{\varepsilon}$-carboxymethyllysine. $J$. Biol. Macromol. 2009, 44, 51-56. [CrossRef] [PubMed]

37. Thornalley, P.J.; Rabbani, N. Detection of oxidized and glycated proteins in clinical samples using mass spectrometry a user's perspective. Biochim. Biophys. Acta 2014, 1840, 818-829. [CrossRef]

38. Bottcher, C.; Roepenack-Lahaye, E.V.; Willscher, E.; Scheel, D.; Clemens, S. Evaluation of matrix effects in metabolite profiling based on capillary liquid chromatography electrospray ionization quadrupole time-of-flight massspectrometry. Anal. Chem. 2007, 79, 1507-1513. [CrossRef] [PubMed]

39. Murthy, U.M.; Liang, Y.; Kumar, P.P.; Sun, W.Q. Non-enzymatic protein modification by the Maillard reaction reduces the activities of scavenging enzymes in Vigna radiata. Physiol. Plant 2002, 115, 213-220. [CrossRef]

40. Sun, W.Q.; Leopold, A.C. The Maillard Reaction and Oxidative Stress during Aging of Soybean Seeds. Physiol. Plant 1995, 94, 94-104. [CrossRef]

41. Monnier, V.M.; Sell, D.R.; Strauch, C.; Sun, W.; Lachin, J.M.; Cleary, P.A.; Genuth, S. The DCCT Research Group The association between skin collagen glucosepane and past progression of microvascular and neuropathic complications in type 1 diabetes. J. Diabetes Complicat. 2013, 27, 141-149. [CrossRef]

42. Marciniak-Darmochwal, K.; Kostyra, H. Influence of nonenzymatic glycosylation (glycation) of pea proteins (pisum sativum) on their susceptibility to enzymatic hydrolysis. J. Food Biochem. 2009, 33, 506-521. [CrossRef]

43. Casey, R.; Domoney, C. Seed Proteins; Shawrey, P.R., Casey, R., Eds.; Springer: Dordrech, The Netherlands, 1999; pp. 171-208. ISBN 978-94-010-5904-6.

44. Gehrig, P.M.; Krzyzaniak, A.; Barciszewski, J.; Biemann, K. Mass spectrometric amino acid sequencing of a mixture of seed storage proteins (napin) from Brassica napus, products of a multigene family. Proc. Natl. Acad. Sci. USA 1996, 93, 3647-3652. [CrossRef] [PubMed]

45. Thermo ScientificTM PierceTM Carboxypeptidase Y and Resin. Available online: https://www.fishersci.co. uk/shop/products/pierce-carboxypeptidase-y-resin/11816744 (accessed on 3 December 2018).

46. Proteinase from Aspergillus Melleus. Available online: https://www.sigmaaldrich.com/catalog/product/ sigma/p4032?lang=en\&region=RU (accessed on 3 December 2018).

47. Protease from Streptomyces Griseus. Available online: https://www.sigmaaldrich.com/catalog/product/ sigma/p5147?lang=en\&region=RU (accessed on 3 December 2018).

48. Breddam, K.; Ottesen, M. Determination of C-terminal sequences by digestion with serine carboxypeptidases: The influence of enzyme specificity. Curlsberg Res. Commun. 1987, 62, 55-63. [CrossRef]

49. Lewis, W.S.; Schuster, S.M. Carboxypeptidase Y stability. J. Biol. Chem. 1991, 266, 20818-20822. [PubMed]

50. Hashimoto, C.; Iwaihara, Y.; Chen, S.J.; Tanaka, M.; Watanabe, T.; Matsui, T. Highly-sensitive detection of free advanced glycation end-products by liquid chromatography-electrospray ionization-tandem mass spectrometry with 2,4,6-trinitrobenzene sulfonate derivatization. Anal. Chem. 2013, 85, 4289-4295. [CrossRef] [PubMed]

51. Taylor, P.J. Matrix effects: The Achilles heel of quantitative high-performance liquid chromatography-electrospray-tandem mass spectrometry. Clin. Biochem. 2005, 38, 328-334. [CrossRef] [PubMed]

52. Rabbani, N.; Ashour, A.; Thornalley, P.J. Mass spectrometric determination of early and advanced glycation in biology. Glycoconj. J. 2016, 33, 553-568. [CrossRef] [PubMed] 
53. Glomb, M.A.; Pfahler, C. Amides are novel protein modifications formed by physiological sugars. J. Biol. Chem. 2001, 276, 41638-41647. [CrossRef] [PubMed]

54. Statland, B.E.; Winkel, P.; Bokelund, H. Variation of serum iron concentration in young healthy men: Within-day and day-to-day changes. Clin. Biochem. 1976, 9, 26-29. [CrossRef]

55. Greifenhagen, U.; Nguyen, V.D.; Moschner, J.; Giannis, A.; Frolov, A.; Hoffmann, R. Sensitive and site-specific identification of carboxymethylated and carboxyethylated peptides in tryptic digests of proteins and human plasma. J. Proteome Res. 2015, 14, 768-777. [CrossRef]

56. Frolov, A.; Bilova, T.; Paudel, G.; Berger, R.; Balcke, G.U.; Birkemeyer, C.; Wessjohann, L.A. Early responses of mature Arabidopsis thaliana plants to reduced water potential in the agar-based polyethylene glycol infusion drought model. J. Plant Physiol. 2017, 208, 70-83. [CrossRef] [PubMed]

57. Greifenhagen, U.; Frolov, A.; Bluher, M.; Hoffmann, R. Site-specific analysis of advanced glycation end products in plasma proteins of type 2 diabetes mellitus patients. Anal. Bioanal. Chem. 2016, 408, 5557-5566. [CrossRef] [PubMed]

58. Mosmann, T. Rapid colorimetric assay for cellular growth and survival: Application to proliferation and cytotoxicity assays. J. Immunol. Methods 1983, 65, 55-63. [CrossRef]

(C) 2019 by the authors. Licensee MDPI, Basel, Switzerland. This article is an open access article distributed under the terms and conditions of the Creative Commons Attribution (CC BY) license (http://creativecommons.org/licenses/by/4.0/). 